EESTI NSV TEADUSTE AKADEEMIA TOIMETISED. 29. KOIDE

GEOLOOGIA. 1980, NR. 1

ИЗВЕСТИЯ АКАДЕМИИ НАУК ЭСТОНСКОЙ ССР. ТОМ 29

ГЕОЛОГИЯ, 1980, № 1

удК $551.794(474.2)$

Хельги КЕССЕЛ

\title{
ВОЗРАСТ ДОННЫХ ОТЛОЖЕНИЙ БАЛТИЙСКОГО МОРЯ В ЗАПАДНО-ЭСТОНСКОМ АРХИПЕЛАГЕ ПО ПАЛИНОЛОГИЧЕСКИМ ДАННЫМ
}

Материалом для биостратиграфического изучения донных отложений служили 21 колонка грунта морского дна, взятые в период с 1966 по 1976 г. сотрудниками Института геологии АН ЭССР с научно-исследовательского судна ИО АН СССР «Профессор Добрынин» и катера «Иольдия» с помощью вибропоршневой трубки (рис. 1). Изучено свыше 500 палинологических образцов донных отложений, отобранных с глубины воды 2,5-54 м. Бо́льшая часть колонок взята в прибрежной зоне о. Сааремаа и в мелководном море Вяйнамери. Две из исследованных колонок были заложены на большой глубине моря у северозападного побережья Эстонии, одна - в центральной части Рижского залива. Высота полученных колонок обычно составляла до 4,5 $\mathbf{M}$. В колонках, взятых с небольшой глубины в море Вяйнамери и в при-

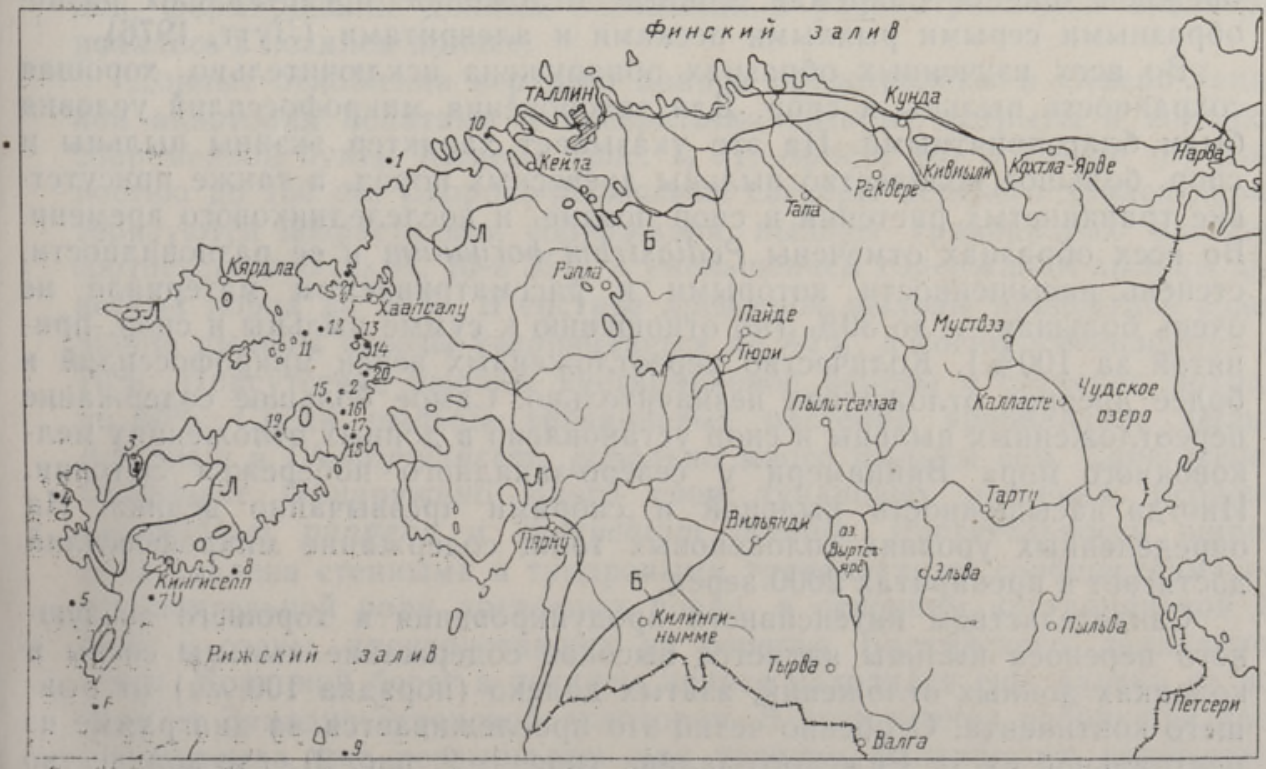

Рис. 1. Расположение колонок донных отложений в прибрежной зоне Западной Эстонии. $E-$ береговая линия Балтийского ледникового озера; $\pi$ - береговая линия Колонки: Ристн (1) Литоринового моря.

Колонки: Ристна (1), Пюссина (2), Кюдема (3), Харилайд (4), Аристе (5), Сырве (6), Ярве (7), Вятта (8), Рижский залив близ о. Рухну (9), Лахепере (10), Суур-Вяйн $(15-18)$, Вяйке-Вяйн $(11-14,19)$, Матсалу $(20)$, Воози (21).

2 ENSV TA Toimetised. G 11980 


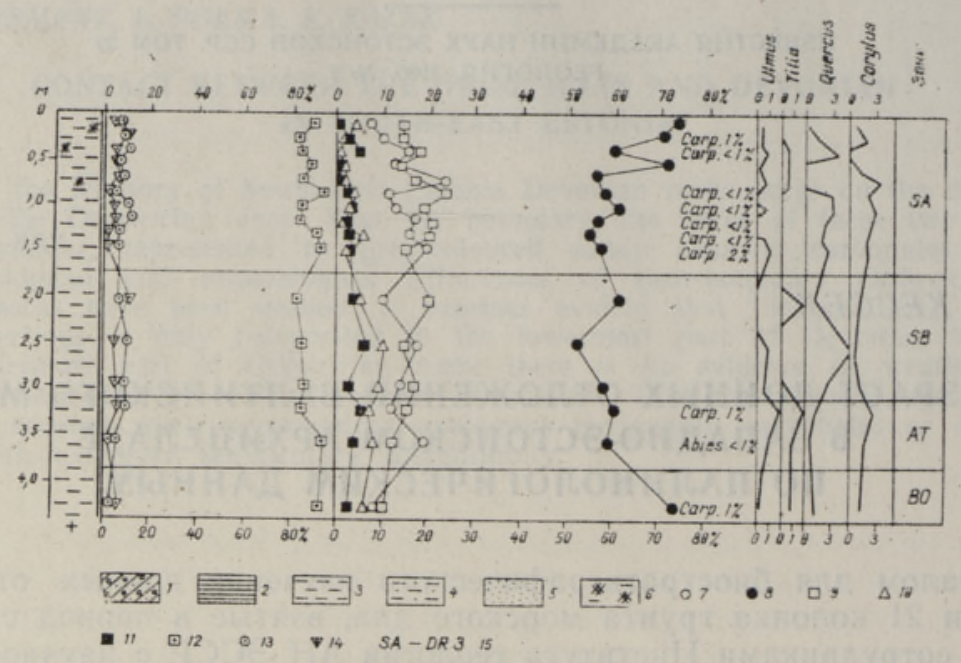

Рнс. 2. Спорово-пыльцевая диаграмма донных отложений колонки Рижского залива. 1 - морена; 2 - ленточная глина; 3 алевриты; 4 - песчанистые алевриты; 5 - пески; 6 - тонкие прослойки органики в алевритах; 7 - пыльца березы; 8 - пыльца сосны; 9 - пыльца ольхи; 10 - пыльца ели; 11 - пыльца широколиственных пород; 12 - пыльда древесных пород и кустарников; 13 - пыльца травянистых растений; 14 - споры; 15 - зоны развития растительности по Каяку и др., 1976.

брежной зоне о. Сааремаа, донные отложения представлены разнообразными серыми рыхлыми песками и алевритами (Лутт, 1976).

Во всех изученных образцах обнаружена нсключительно хорошая сохранность пыльцы и спор. Для захоронения микрофоссилий условия были благоприятными. На это указывает характер экзины пыльцы и . спор, большое количество пыльцы древесных пород, а также прнсутствие травянистых растений и спор поздне- и послеледникового времени. Во всех образцах отмечены Pediastrum boryanum и ее разновидности, степень насыщенности которыми в рассматриваемом материале не очень большая - до $30 \%$ (по отношению к сумме пыльцы и спор, прннятой за $100 \%$ ). Количество переотложенных зерен микрофоссилий в более древних отложениях незначительно. Самое большое содержание переотложенных пыльцы и спор установлено в донных отложеннях мелководного моря Вяйнамери у северо-западного побережья Эстонин. Иногда насыщенность пыльцой и спорами чрезвычайно велика. На определенных уровнях голоценовых толщ содержание микрофоссилий достигает в препаратах 2000 зерен.*

Свидетельством интенсивного продуцирования и хорошего воздушного переноса пыльцы является высокое содержание пылыцы сосны в колонках донных отложений, взятых далеко (порядка 100 км) от бывшего континента. Особенно четко это прослеживается на диаграмме из центральной части Рижского залива (рис. 1, 9; рнс. 2), где количество пыльцы сосны составляет $52-73 \%$.

В результате палинологнческого анализа изученные донные отложения четко подразделяются на поздне- и послеледниковые.

* Сравнительный подсчет пыльцы и спор производился во всех образцах с одного препарата, покрытого покровным стеклом размером $18 \times 18$ м.. 
Более дробное стратиграфическое подразделение позднеледниковых донных отложений довольно затруднено, так как климатические изменения в позднем плейстоцене на территории Западной Эстонии улавливаются слабо. О небольших колебаниях климата того времени свидетельствуют характер и состав травянистых растений и кустарниковых берез и соотношение древесных пород, а также изменение литологического характера отложений, например, в колонках Кюдема (рис. 1,3$)$, Сырве (6), Ярве (7), Вятта (8) и Матсалу (20). Установленные в них под отложениями верхнего дриаса сравнительно мощная ленточная глина и тонкие слои алеврита и пелита содержат немного пыльцы и спор. Преобладает пыльца древесных пород (до 85\%), в основном сосны (до $90 \%)$ и березы $(15-25 \%)$, присутствует много переотложенной пыльцы, особенно ольхи (порядка 20\%). В . составе трав (до 10\%) преобладают полыни и маревые. Рассматриваемые донные отложения отнесены нами условно к среднему дриасу и частично к аллереду.

Накопление донных отложений Западно-Эстонского архипелага начиналось в сложных палеогеографических условиях, так как основная часть акватории в начале позднеледниковья, включая вторую половину аллереда, была покрыта ледником (Серебрянный, Раукас, 1967 и др.). В районах побережья четко прослеживается зона краевых ледниковых образований паливереской стадии, образовавшаяся 11500 11000 л. н. Среднедриасовая и аллередская растительность из-за близледниковых условий была развита очень слабо. К тому же ближайшие материковые части - Пандивереская и Сакалаская возвышенности находились сравнительно далеко. Полное освобождение территории Северной и Северо-Западной Эстонии от ледникового покрова произошло, по всей вероятности, в конце аллереда. Согласно этой концепции, формирование донных отложений в рассматриваемой акватории началось в позднем дриасе.

Донные отложения верхнего дриаса представлены в Северо-Западной акватории. пелитами и алевритами, которые вскрыты в колонках современной бухты Кюдема (рис. 1, 3), Аристе (5) и Сырве (6) мощностью до 150 см. Спорово-пыльцевые спектры верхнего дриаса характеризуются возрастанием содержания пыльцы травянистых растений соответственно до 65,40 и $35 \%$ и уменьшением содержания пыльцы древесных пород до $35 \%$. В составе древесной пыльцы процентное содержание пыльцы березы увеличивается до $40 \%$, а сосны уменьшается до $70 \%$. Присутствие пыльцы кустарниковой березы в спектрах доходит до $60 \%$. Среди пыльцы травянистых растений преобладает пыльца Artemisia и Chenopodiaceae, довольно много пыльцы сем. Cyperaceae и Gramineae. Обнаружено много спор тундровых растений, особенно Lycopodium pungens и Botrychium boreale. Растительность широко представлена степными и тундровыми травянистыми сообществами при незначительной роли древесных пород, в основном кустарниковой березы и сосны, произраставших на берегах Балтийского ледникового озера. Коренной берег в позднем дриасе находился еще далеко на востоке от Западно-Эстонской акватории. В этот период небольшая часть о. Сааремаа уже возвышалась над уровнем Балтийского ледникового озера. Основным источником пыльцы и спор в позднеледниковье все же служили прибрежные районы материковой части Әстонии и Латвии.

Пребореальные донные отложения, или отложения Иольдиевого моря, прослеживаются в колонках Кюдема (рис. 1, 3) и Аристе (5) мощностью до $80 \mathrm{~cm}$. В спорово-пыльцевых спектрах этих отложений господ- 
ствует пыльца древесных пород, роль пыльцы травянистых растений сокращается до $20 \%$. Среди древесных пород доминируют сосна (до $60 \%$ ) и береза (до $40 \%$ ). Пыльца березы представлена в основном пыльцой Betula Albae. Содержание пыльцы Betula humilis и B. nana не превышает $15 \%$, пыльцы ольхи и ели доходит до $5 \%$. Среди пыльцы травянистых растений наиболее часто встречается пыльца Artemisia и представителей сем. Cyperaceae, Gramineae, спорадически обнаружены зерна водных растений, таких как Typha и Sparganium. Увеличивается количество спор сфагновых мхов и папоротников сем. Polypodiaceae. Среди споровых присутствуют еще тундровые виды Lycopodium alpinum, но содержание их не превышает $5 \%$. До сих пор в пределах моря Вяйнамери пребореальные донные отложения не установлены. Причиной этого является, вероятно, более интенсивный размыв морского дна в связи со значительными колебаниями уровней Иольдиевого моря и Анцилового озера.

Бореальные донные отложения, или отложения Анцилового озера, вскрыты колонками Кюдема (рис. 1, 3), Харилайд (4), Аристе (5), Сырве (7), Вятта (8) и Суур-Вяйн (17) мощностью от 25 до 200 см. Наиболее полно эти отложения обнажены в 4 колонках современной бухты Кюдема. В общем составе спорово-пыльцевых спектров бореального периода значительную часть составляет пыльца древесных пород (до $85 \%$ и даже больше). Содержание пыльцы травянистых растений и спор колеблется от 8 до 15\%. Пыльца древесных пород представлена в основном пыльцой сосны (Pinus sylvestris), содержание которой достигает 90\%. Пыльца других древесных пород, таких как Betula и Alnus, составляет до 20 и $10 \%$ соответственно. Пыльца лещины и широколиственных пород (прежде всего Ulmus) появляется, но содержание ее не превышает $5 \%$. Пыльца ели по-прежнему составляет ничтожное количество - до $2 \%$. Среди спор доминируют споры Polypodiaceae (до 90\%), мало спор Lycopodium и Sphagnum. Возрастает также роль пыльцы мезофильного разнотравья, преимущественно Leguminosae и Rosaceae и особенно Filipendula.

Атлантические донные отложения, или отложения Литоринового моря, прослеживаются в колонках Кюдема (рис. 1, 3), Харилайд (4), Лахепере (10), Рижский залив (9), Суур-Вяйн (17) и Матсалу (20) мощностью от 25 до $220 \mathrm{~cm}$. Содержание пыльцы и спор в препаратах этих отложений в некоторых случаях обильное, например в колонке Матсалу. Спектры атлантических донных отложений характеризуются сравнительно большим количеством пыльцы широколиственных (представлены Ulmus и Tilia, в меньшей мере Quercus), а также пыльцой лещины и ольхи. Количество термофильных пород увеличивается в спектрах вверх по разрезу до $20 \%$, количество пыльщы сосны сокращается до $30 \%$, пыльцы березы составляет до $20 \%$. Из споровых растений в отложениях атлантического периода определены папоротники Dryopteris и Polypodium, а также некоторые виды Lycopodium. Среди травянистых растений преобладает сем. Gramineae при широком распространении разнотравья, в частности Compositae, Caryophyllaceae, Umbelliferae и Rubiaceae. В составе пыльцы водных растений отмечается пыльца Typha и Sparganium.

Суббореальные донные отложения, или отложения Лимниевого моря, обнаружены в колонках Пюссина (рис. 1, 2), Ярве (7), Лахепере (10), Рижский залив (9), Матсалу (20) мощностью от 40 до 200 cм. По сравнению с атлантическими отложениями в суббореальных меньше пыльщы 


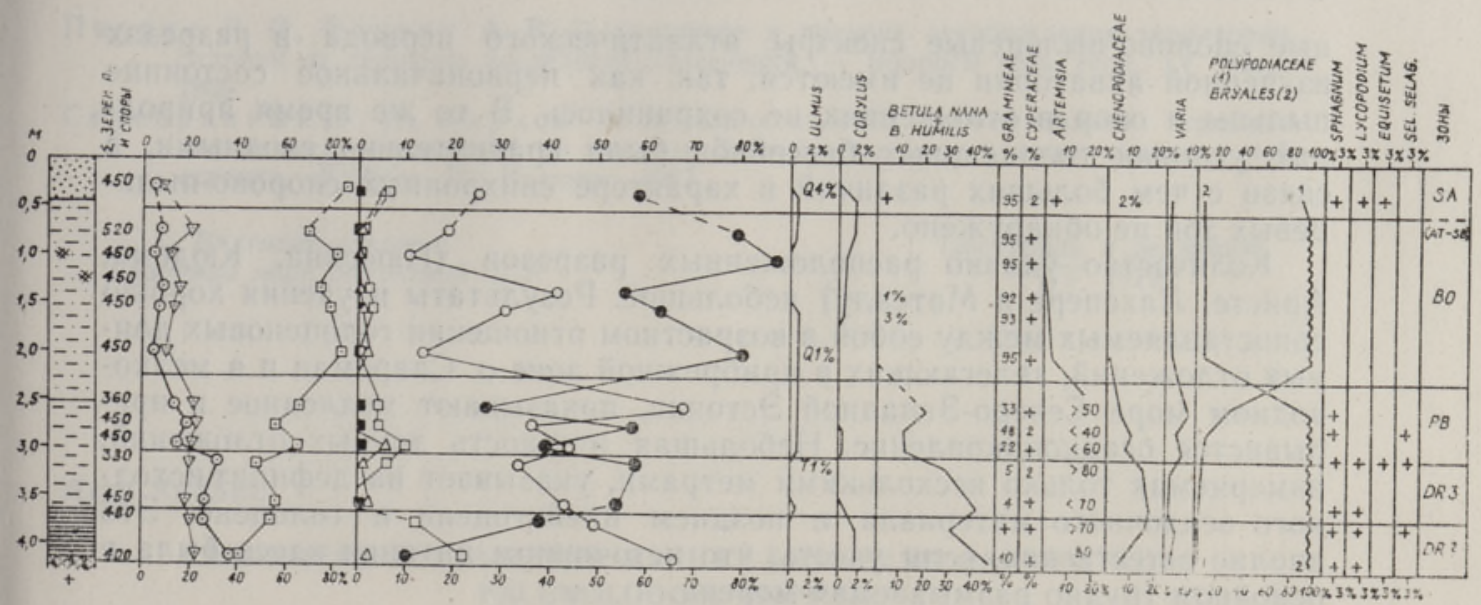

Рис. 3. Спорово-пыльцевая диаграмма донных отложений колонки Аристе. Условные обозначения см. на рис. 2.

широколиственных и ольхи. Количество пыльцы березы и сосны возрастает, а лещины - уменьшается. Пыльца граба и бука обнаружена в виде единичных зерен. Количество пыльцы травянистых растений в суббореальных спектрах незначительно увеличивается за счет пыльцы сем. Cyperaceae и Gramineae.

Субатлантические донные отложения, или отложения Лимниевого моря, установлены в колонках Ристна (рис. 1, 1), Пюссина (2), Аристе (5), Вятта (8), Лахепере (10), в пяти колонках Вяйке-Вяйн $(11-14,19)$, Суур-Вяйн (15-18) и Матсалу (20). Мощность их колеблется от 20 до 330 см. Спорово-пыльцевые спектры субатлантического периода по составу близки спектрам суббореального периода, но отличаются от них значительным содержанием пыльцы ели (до 20\%), которая особенно обильна на некоторых уровнях верхней и нижней частей колонок ВяйкеВяйн (рис. $1,11-14,19)$ и Воози $(21)$. На диаграмме сплошную кривую образуют пыльца граба и бука.

Закономерное изменение состава пыльцы и спор по вертикальному разрезу донных отложений отражает общие изменения климатических условий и растительных ассоциаций главным образом на островах и на прилегающей к Западной Эстонии территории. На спорово-пыльцевых диаграммах но характеру и составу спектров выделяются 6 комплексов, которые связываются с определенными спорово-пыльцевыми зонами. Из-за недостаточной густоты отбора проб (через 10 и 20 cм) нам не всегда удавалось выделить все эти зоны и часто приходилось ограничиваться выделением лишь отложений поздне- и послеледниковья, так как спорово-пыльцевые спектры в составленных диаграммах в известной мере сливались (рис. 2 и 3 ).

Палеогеографические условия и сложный характер осадконакопления Балтийского моря в поздне- и послеледниковье, когда периоды седиментации сменялись периодами размыва и перераспределения осадочного исходного материала, привели к тому, что разрез донных отложений разновозрастных стадий в мелководном море архипелага является неполным. Вследствие этого соответствующие спорово-пыльцевые спектры оказываются усредненными, и зональное развитие растительности отражается в спектрах только в общих чертах. Например, типич- 
ные спорово-пыльцевые спектры атлантического периода в разрезах изученной акватории не имеются, так как первоначальное состояние пыльцы и спор в отложениях не сохранилось. В то же время природные условия голоценовых бассейнов были сравнительно сходными, в связи с чем больших различий в характере синхронных спорово-пыльцевых зон не обнаружено.

Количество удачно расположенных разрезов (Пюссина, Кюдема, Аристе, Лахепере и Матсалу) небольшое. Результаты изучения хорошо сопоставляемых между собой в возрастном отношении голоценовых донных отложений, залегающих в прибрежной зоне о. Сааремаа и в мелководном море Северо-Западной Эстонии, показывают медленное и прерывистое осадконакопление. Небольшая мощность донных отложений, измеряемая только несколькими метрами, указывает на дефицитисходного осадочного материала в позднем плейстоцене и голоцене. Это вполне естественно, если учесть, что источником питания здесь была в основном трудно размываемая морена.

В позднем голоцене в рассматриваемом архипелаге, а также в глубоких бухтах предглинтовой полосы Северной Эстонии (Кессел, Порк, 1971) и в глубоководных впадинах щентральной и южной части Балтики (Кессел и др., 1973) накоплялись донные отложения небольшой мощности. Наоборот, в пределах современного мелководного моря Вяйнамери (рис. $1,11-18$ ) распространяются донные отложения верхнего голоцена сравнительно большой мощности - до $140 \mathrm{~cm}$. Причиной этого, наверно, являются повторное переотложение и сильное перемешивание более ранних донных отложений. Этот район архипелага в бореале и атлантике представлял собой прибрежную абразионноаккумулятивную зону с глубинами порядка 50 и 25 м. Начиная с конца. литориновой стадии море Вяйнамери со всех сторон было ограничено сушей, и преобладающий в это время открытый берег оказался защищенным от сильного волнения благодаря наличию материка в виде центральной части о-вов Хийумаа, Сааремаа и Муху. В суббореале и субатлантике глубина моря в этом районе архипелага уменьшилась до $10 \mathrm{M}$.

Постоянное уменьшение глубины акваторин, а также временные большие колебания уровня воды в начале иольдиевой стадии и в конце анциловой и литориновой стадий явнлись основными факторами, определившими особенности формирования спорово-пыльцевых спектров донных отложений по разрезу изученных колонок.

Автор выражает глубокую благодарность К. Орвнку, Я. Лутту и Ю. Каску за предоставление образцов из геологических разрезов донных отложений архипелага для палинологических анализов.

\section{ЛИТЕРАТ У РА}

К аяк К., Кессел Х., Лий вранд Э. и др. Местная стратиграфическая схема четвертичных отложений Эстонии. - В кн.: Стратиграфия четвертичных отложеннй Прибалтики. Вильнюс, 1976, с. 4-52.

Кессел Х,, Давыдова Н,, Бл ажчи шин А. Пыльца и диатомовые из колонок глубоководных впадин Балтики. - Нзв. АН ЭССР. Хим. Геол., 1973, т. 22, № 4 , c. $345-354$.

Кессел Х. Я., Порк М. И. К стратиграфии донных отложений Балтики в пределах Әстонии. - В кн.: Палинологические исследования в Прибалтике. Рига, 1971.

Лутт. Я. О распределении тяжелых минералов по гранулометрическому спектру в поверхностном слое донных осадков восточной части Вяйнамери (Балтийское море). - Изв. АН ЭССР. Хим. Геол., 1976, т. 25, № 1, с. 66-77. 
Пи ррус Р. О., Р аука с А. В. О характере и времени освобождения территории Эстонии от ледников последнего оледенения. - Вопросы четв. геол., IV. Рига, 1969.

Серебрянный Р. Л., Р аука с А. В. Сопоставление готигляциальных краевых ледннковых образований во впадине Балтийского моря и прилегающих к ней странах. «Baltica», III. Вильнюс, 1967.
Ннститут геологии
Академии наук Эстомской ССР
Поступила в редакцию
$7 / \mathrm{V} \quad 1979$

\section{Helgi KESSEL}

\section{LAANEMERE PÓHJASETETE VANUS LAANE-EESTI SAARESTIKUS PALUNOLOOGIA ANDMEIL}

Artiklis on esitatud Lääne-Eesti saarestiku põhjasetete õietolmu ja eoste komplekside iseloomustus peamiselt kuue kliimaperioodi palünoloogiliste tunnuste alusel. Uurimise tulemusena on selgunud, et vaid ülemisele drüüasele, preboreaalile, boreaalile, atlantikumile, subboreaalile ja subatlantikumile vastavate komplekside vahel on olulisi erinevusi.

\section{Helgi KESSEL}

\section{THE AGE OF THE BOTTOM DEPOSITS FROM THE WEST-ESTONIAN ARCHIPELAGO OF THE BALTIC SEA, ON THE BASIS OF PALYNOLOGICAL DATA}

The study of palynological material collected from 21 boreholes in bottom deposits, mainly in the West-Estonian Archipelago revealed rather typical features enabling a stratigraphic definition of 6 climatic periods. The complexity of sedimentation processes in the Baltic Sea during the Late Pleistocene and Holocene, when periods of sedimentation alternated with those of outwashing and redistribution of primary sedimentary material, brought along a discontinuous bedding of deposits belonging to different-aged stages in the shallow water of the archipelago.

In the Holocene, the natural conditions of ancient basins distributed within the small boundaries of the archipelago were rather similar and did not bring about any great differences in the character of the synchronous spore and pollen zones of the above deposits. The stratigraphic zones characterized by spore and pollen complexes of bottom deposits of the West-Estonian Archipelago have been correlated with the zones according to the scheme of continental (lacustrine and bog) deposits. 